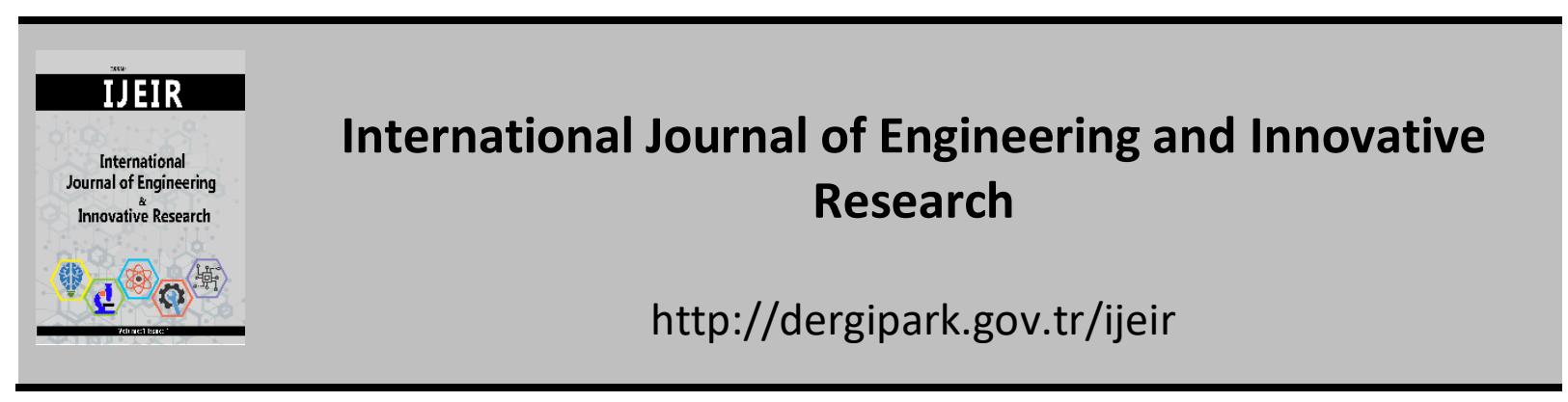

\title{
MODELLING OF A FLAT PLATE SOLAR COLLECTOR SYSTEM USING RESPONSE SURFACE METHODOLOGY
}

\author{
Eghosa Omo-Oghogho ${ }^{1 *} \mathbb{B}$, Sufianu Adeiza Aliu ${ }^{1}$ \\ ${ }^{1}$ Department of Mechanical Engineering, University of Benin, P.M.B 1154, Ugbowo, Nigeria.
}

https://doi.org/10.47933/ijeir.727423

*Corresponding Author: eghosa.omo-oghogho@uniben.edu

(Received: 27.04.2020; Revised: 23.05.2020; Accepted: 30.06.2020)

\begin{abstract}
In this study, performance analysis of flat plate solar collector has been carried out analytically. A comprehensive mathematical modelling of thermal performance is modelled using Response Surface Methodology and optimal geometrical and thermodynamic parameters are predicted pertaining to optimum performance of the system. In this study a model was developed for evaluating and predicting the efficiency, outlet temperature and performance of a flat plate solar collector considering the hour angle, day and input temperature as input parameters. In the cause of the work it was found that the days and months close to the beginning of the year (January, February, March and April) yielded higher outlet temperature and solar radiation due to dry season, while the months at the middle of the year showed lower outlet temperature and solar radiation due to the rainy season. The months towards the ending of the year also showed higher outlet temperature and solar radiation respectively.
\end{abstract}

Keywords: Hour Angle, Day Temperature, Efficiency, Design of Experiment, Solar Collector.

\section{INTRODUCTION}

The role of energy becomes increasingly important to fulfil the needs of modern societies and to sustain fast economic and industrial growth worldwide. In view of the world's depleting fossil fuel reserves and environmental threats, development of renewable energy sources receives importance as an alternative to serve as a form of power source. Solar energy stands out as one of the renewable energy resources that has continuously meet the energy demand in the world, as a result of the availability of sunshine on a daily basis. Though it is location and time dependent, it requires efficient collection and storage systems for economic use.

Solar energy can assist in some areas like water treatment, hot/process water for domestic and industrial use. One of the easiest ways to utilize solar energy for heating applications is to convert it into thermal energy by using solar collectors.

Solar energy collectors are special kinds of heat exchangers that transform solar energy to internal energy of water. The thermal analysis of the collectors is very complicated because all the possible modes of heat transfer and radiation are taken into consideration. The determination of the heat losses coefficient is the main goal of an energetic analysis because this leads to the determination of the useful energy rate from the solar collector. 
Several studies which compare experimentally results with results base on Computational Fluid Dynamics (CFDs) have been published in recent times [1]. Many researchers have used exergy analysis in order to improve the efficiency of collectors by decreasing the losses. Hamed and Ban, [2] used MATLAB to optimize a flat plate collector with this method. Parametrical analysis is also useful in the analysis of flat plate solar collector, as it helps in determining optimum parameters which in turn influences the output efficiency. Hottel and Woertz, [3] calculated the overall heat loss coefficient and the collector efficiency under different conditions such as the absence of cover, with single and double glazing under different ambient conditions, tilt angles, wind speeds, emissivity of both glass cover and absorber plate. Paulescu et al, [4] discussed the influence of various parameters on the efficiency of solar collectors and concluded that at low solar insolation in the range of $200-600 \mathrm{~W} / \mathrm{m}^{2}$ double glazed collectors are superior to single glazed. Stanciu and Stanciu, [5] examined the performance by changing the colors of solar collector. Based on the transmittance-absorptance result of various colored collectors the hypothetical performances of these collectors were calculated using the HottelWhillier-Bliss 1-D steady-state model given by [6]. By these experiments they concluded that the color of the collector plays a major role in thermal efficiencies of the collectors.

In this study Response Surface Methodology (RSM) was used as a modelling tool, considering both input and output parameters/responses.

\section{MATERIALS AND METHOD}

The purpose of the model was to predict the performance of the flat plate solar collector using hour angle, day and inlet temperature as input parameters. The output parameters or responses that were obtained are outlet temperature and efficiency respectively. This modelling enabled the development of a new mathematical model to also validate the experimental work that was later carried out.

The modelling of the system was done using Response Surface Methodology (RSM), boundary conditions and the considerations of the design during the thermodynamic analysis. The design was carried out using factorial design on design expert to check for every limit on each block of the values to ascertain the correlation between the input variables and the output variables. The Box Behnkens design was used for the full factorial design.

Box-Behnken designs are response surface designs, specially made to require only 3 levels, coded as $-1,0$, and +1 . Box-Behnken designs are available for 3 to 10 factors. They are formed by combining two-level factorial designs with incomplete block designs. This procedure creates designs with desirable statistical properties but, most importantly, with only a fraction of the experiments required for a three-level factorial. Because there are only three levels, the quadratic model is appropriate. Blocking options are also offered for most of these designs.

You may also add categorical factors to this design. This will cause the number of runs generated to be multiplied by the number of combinations of the categorical factor levels.

Table 1 provides the design of experiment that was used for the analysis and modelling. The input factors and the output factors or response are considered during the design of experiment, the input factors are hour angle, day and inlet temperature. The output/response are input temperature and efficiency. 


\section{Hour Angle (Degrees)}

The hour angles affect the design because the position of the sun on a particular day is dependent on the local time of the place. The solar noon was considered to be $0^{0}$ and every hour was counted as $15^{0}$. Hours before noon took a negative sign while hours after noon was positive for example, 9:00A.M in the morning is 3 hrs from solar noon thus was read as $15 \times 3=45$, since it is before noon, it is therefore recorded as $-45^{0}$. The design considered times from 9:00A.M to 3:00P.M.

\section{Day (number from $1^{\text {st }}$ January)}

The days were counted from $1^{\text {st }}$ of January, so it is counted from 1 to 365 days. The day greatly affects the amount of solar radiation on the surface as the distance from the sun varies and the position of the specific location changes as the earth revolves around the sun.

\section{Inlet Temperature (Kelvin)}

The Inlet temperature of the fluid is a factor that will greatly affect the efficiency of the collector. The inlet temperature of the fluid determines the outlet temperature when all other factors remain constant. The Inlet temperature was varied from $295 \mathrm{~K}$ to $353 \mathrm{~K}$.

Table 1. Design of experiment.

\begin{tabular}{|l|l|l|c|c|c|c|c|}
\hline $\begin{array}{l}\text { St } \\
\mathbf{d}\end{array}$ & $\begin{array}{l}\text { Ru } \\
\mathbf{n}\end{array}$ & Block & $\begin{array}{c}\text { Factor 1 } \\
\text { A:Hour Angle } \\
\text { (deg) }\end{array}$ & $\begin{array}{c}\text { Factor } \\
\mathbf{2} \\
\text { B:Day }\end{array}$ & $\begin{array}{c}\text { Factor 3 } \\
\text { C: Inlet } \\
\text { Temp.(K) }\end{array}$ & $\begin{array}{c}\text { Response } \\
\mathbf{1} \\
\text { Efficiency }\end{array}$ & $\begin{array}{c}\text { Response 2 } \\
\text { Outlet Temp. } \\
\text { (K) }\end{array}$ \\
\hline 3 & 1 & Block 1 & -45.00 & 365.00 & 324.00 & 0.72 & 361.97 \\
\hline 8 & 2 & Block 1 & 45.00 & 183.00 & 353.00 & -0.27 & 351.88 \\
\hline 15 & 3 & Block 1 & 0.00 & 183.00 & 324.00 & 0.59 & 336.56 \\
\hline 6 & 4 & Block 1 & 45.00 & 183.00 & 295.00 & 0.93 & 314.22 \\
\hline 5 & 5 & Block 1 & -45.00 & 183.00 & 295.00 & 0.93 & 314.22 \\
\hline 14 & 6 & Block 1 & 0.00 & 183.00 & 324.00 & 0.59 & 336.56 \\
\hline 17 & 7 & Block 1 & 0.00 & 183.00 & 324.00 & 0.59 & 336.56 \\
\hline 10 & 8 & Block 1 & 0.00 & 365.00 & 295.00 & 0.88 & 342.25 \\
\hline 1 & 9 & Block 1 & -45.00 & 1.00 & 324.00 & 0.73 & 362.36 \\
\hline 16 & 10 & Block 1 & 0.00 & 183.00 & 324.00 & 0.59 & 336.56 \\
\hline 7 & 11 & Block 1 & -45.00 & 183.00 & 353.00 & -0.27 & 351.88 \\
\hline 4 & 12 & Block 1 & 45.00 & 365.00 & 324.00 & 0.72 & 361.97 \\
\hline 13 & 13 & Block 1 & 0.00 & 183.00 & 324.00 & 0.59 & 336.56 \\
\hline 12 & 14 & Block 1 & 0.00 & 365.00 & 353.00 & 0.52 & 375.12 \\
\hline 2 & 15 & Block 1 & 45.00 & 1.00 & 324.00 & 0.73 & 362.36 \\
\hline 11 & 16 & Block 1 & 0.00 & 1.00 & 353.00 & 0.52 & 375.08 \\
\hline 9 & 17 & Block 1 & 0.00 & 1.00 & 295.00 & 0.88 & 342 \\
\hline
\end{tabular}

\section{RESULTS AND DISCUSSION}

The model was developed using Response Surface Methodology. The study type uses was Response Surface Methodology a technique that can be used to study the effect of two or more constraints in a process, the design considered was the Box-Behnkn which is an independent quadratic design, it does not contain an embedded factorial design and the design model chosen was the quadratic from. The input factors were hour angle, day and inlet temperature as shown in Table 2 and table 3 respectively. The responses where efficiency and outlet temperature respectively. 
Study type: Response surface

Design: Box-Behnken

Design model: Quadratic

Table 2. Design model summary 1.

\begin{tabular}{|c|c|c|c|c|c|c|c|c|c|}
\hline Factor & Name & Units & Type & $\begin{array}{c}\text { Low } \\
\text { actual }\end{array}$ & $\begin{array}{c}\text { High } \\
\text { actual }\end{array}$ & $\begin{array}{c}\text { Low } \\
\text { coded }\end{array}$ & $\begin{array}{c}\text { High } \\
\text { coded }\end{array}$ & Mean & $\begin{array}{c}\text { Std. } \\
\text { dev }\end{array}$ \\
\hline A & $\begin{array}{c}\text { Hour } \\
\text { angle }\end{array}$ & Degree & Numerical & -45.0 & 45.0 & 1.0 & 1.0 & 1.0 & 30.87 \\
\hline B & Day & & Numerical & 1.0 & 365.0 & -1.0 & 1.0 & 183.0 & 124.85 \\
\hline C & $\begin{array}{c}\text { Inlet } \\
\text { temp. }\end{array}$ & K & Numerical & 295.0 & 353.0 & -1.0 & 1.0 & 324.0 & 19.894 \\
\hline
\end{tabular}

Table 3. Design model summary 2.

\begin{tabular}{|c|c|c|c|c|c|c|c|c|c|c|c|}
\hline \multirow{2}{\approx}{$\Xi$} & Name & $\begin{array}{c}\text { Unit } \\
\text { S }\end{array}$ & Obs & Analysis & Min & max & Mean & Std dev & Ratio & $\begin{array}{c}\text { Tran } \\
\text { s }\end{array}$ & Model \\
\hline Y1 & $\begin{array}{c}\text { Efficie } \\
\text { ncy }\end{array}$ & $\%$ & 17 & $\begin{array}{c}\text { Polynomi } \\
\text { al }\end{array}$ & 0.270 & 0.930 & 0.586 & 0.340 & -3.44 & none & $\begin{array}{c}\text { Rquadrat } \\
\text { ic }\end{array}$ \\
\hline Y2 & $\begin{array}{c}\text { Outlet } \\
\text { temp }\end{array}$ & $\mathrm{K}$ & 17 & $\begin{array}{c}\text { Polynomi } \\
\text { al }\end{array}$ & 314.2 & 375.1 & 346.9 & 17.6 & 1.19 & none & $\begin{array}{c}\text { Quadrati } \\
\text { c }\end{array}$ \\
\hline
\end{tabular}

Table 2 and 3 present the design summary that involves the input and the response using a quadratic model and activity using a linear model.

\subsection{Graph Columns}

The graph columns display the correlation between a response and an input factor. It displays the response on the vertical axis while the input on the horizontal axis. The different factors can be selected to check the following situations:

It is used to view the Block effects. Plot the response versus the input to visually determine whether the input were influential or not. It is used to gather information about the practical importance of factors that are not statistically significant. For instance, you may not want to include a factor in the model because their effect on the response is very low.

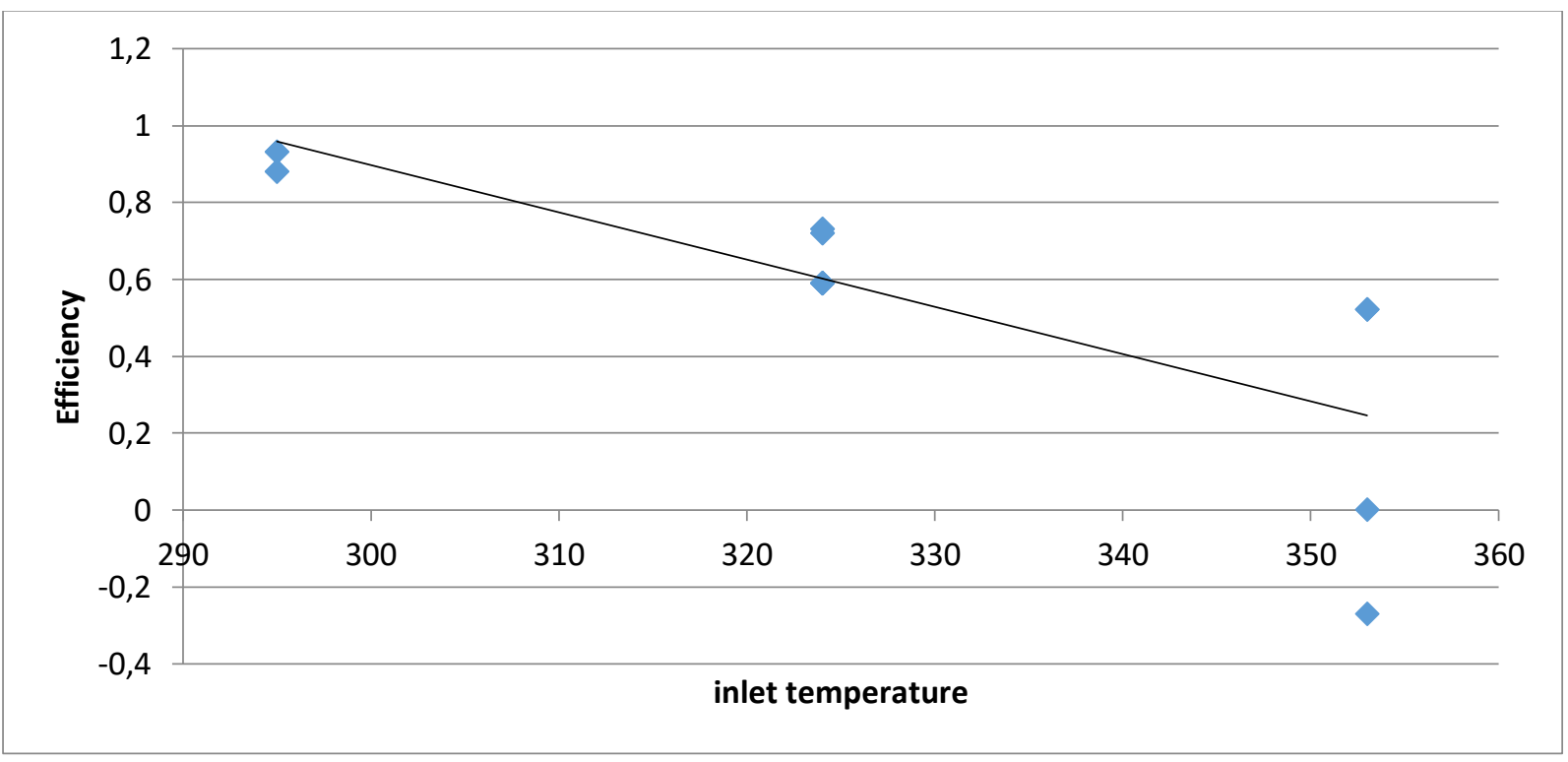

Figure 1. A graph of efficiency against inlet temperature. 
Figure 1 shows the correlation between the input parameter and the response parameter. The efficiency is the response parameter and the inlet temperature is the input parameter. An increase in inlet temperature leads to a decrease in efficiency. This shows that the inlet temperature does not have a positive effect on the system. A correlation of -0.788 was achieved after using Response Surface Methodology, this shows there is no correlation between the input parameter and the response parameter.

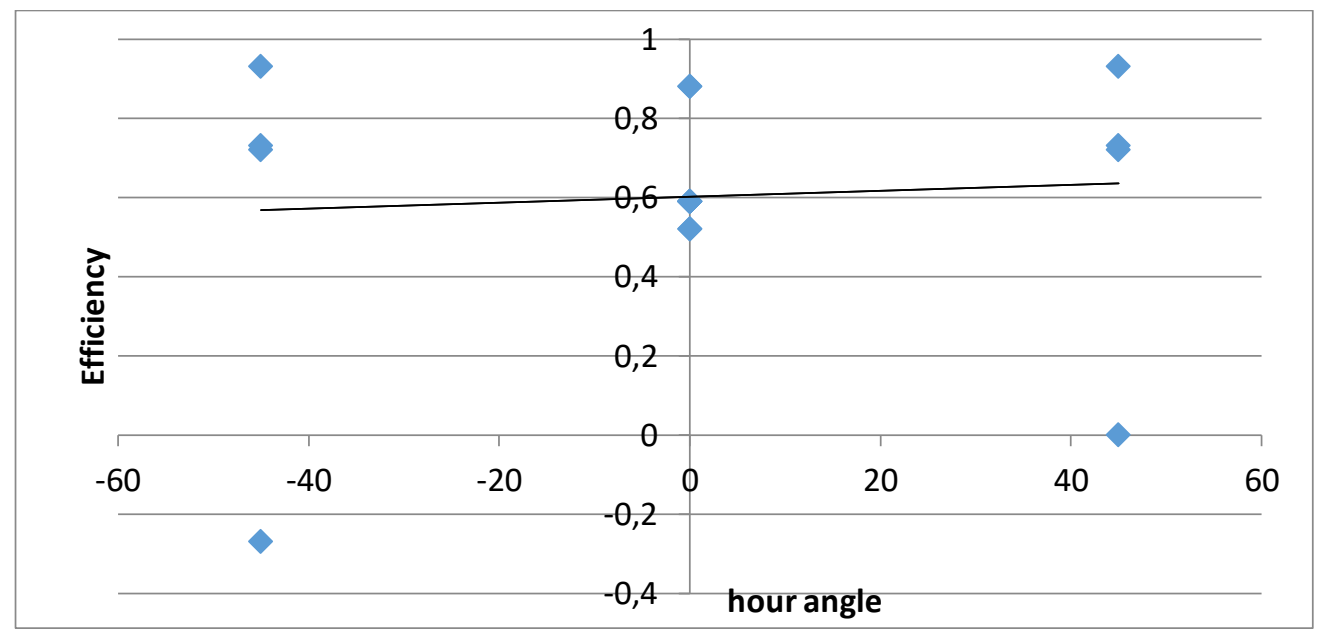

Figure 2. A graph of efficiency against hour angle.

Figure 2 shows the correlation between the input parameter and the response parameter. The efficiency is the response parameter and the hour angle is the input parameter. An increase in the hour angle does not give a significant increase in the efficiency. A correlation of 0.000 was achieved after Response Surface Methodology was employed, this shows that there is no correlation between the input parameter (hour angle) and the response (efficiency). As such there is no significant effect on the response.

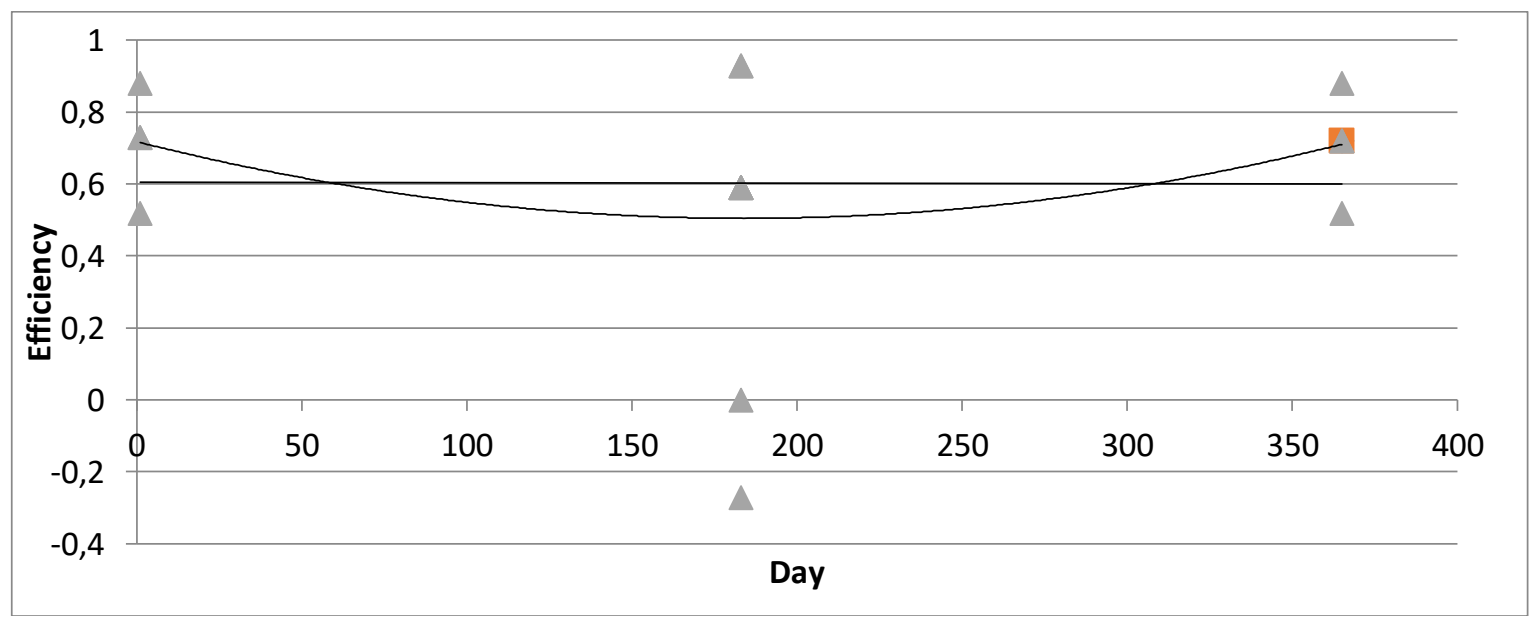

Figure 3. A graph of efficiency against day.

Figure 3 shows the correlation between the input parameter and the response parameter. The efficiency is the response parameter and the day is the input parameter. An increase in the day does not give a significant increase in the efficiency. A correlation of -0.005 was achieved after Response Surface Methodology was used, this indicates that there is no correlation between the input factor and the response parameter. 


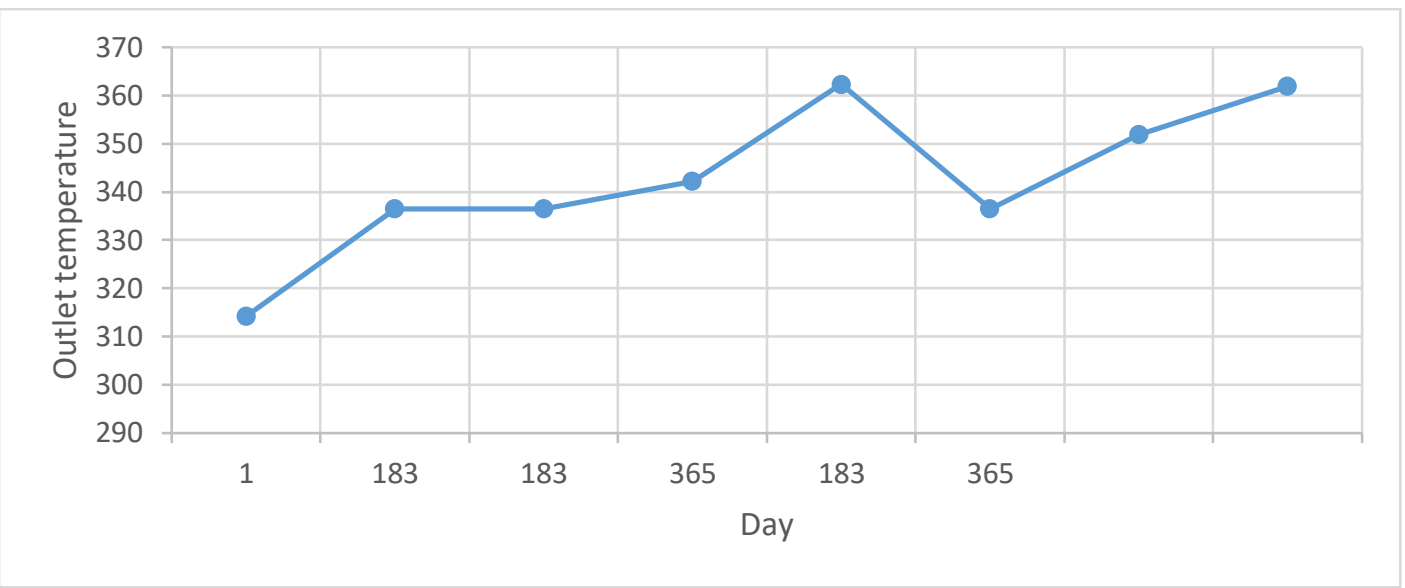

Figure 4. A graph of outlet temperature against day.

Figure 4 shows the correlation between the input parameter and the response parameter. The outlet temperature is the response parameter and the day is the input parameter. An increase in the number of days produced an unsteady performance as related to the outlet temperature. A correlation of -0.002 was achieved, this shows that there is no correlation between the input factor and the response parameter.

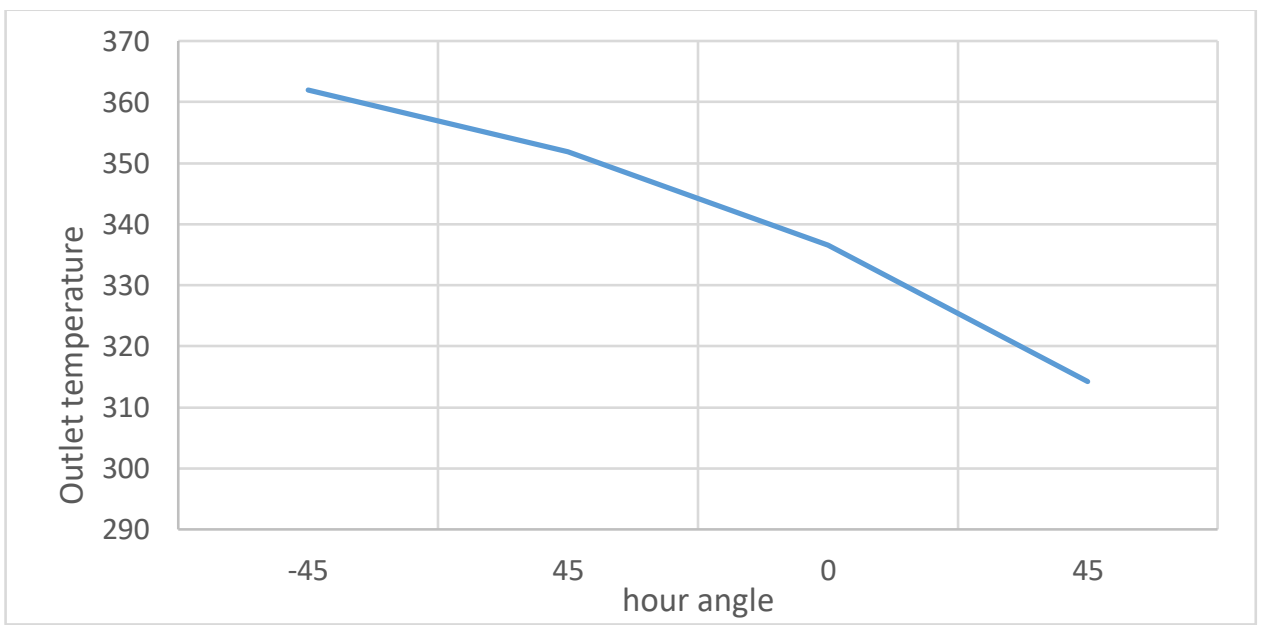

Figure 5. A graph of outlet temperature against hour angle.

Figure 5 shows the correlation between the input parameter and the response parameter. The outlet temperature is the response parameter and the hour angle is the input parameter. As hour angle increased there was a decrease in output temperature, this shows that the hour angle does not have a positive effect on the system. A correlation of 0.000 was achieved using Response Surface methodology, this shows that there is no correlation between the input parameter (hour angle) and the response (outlet temperature). As such there is no significant effect on the response. 


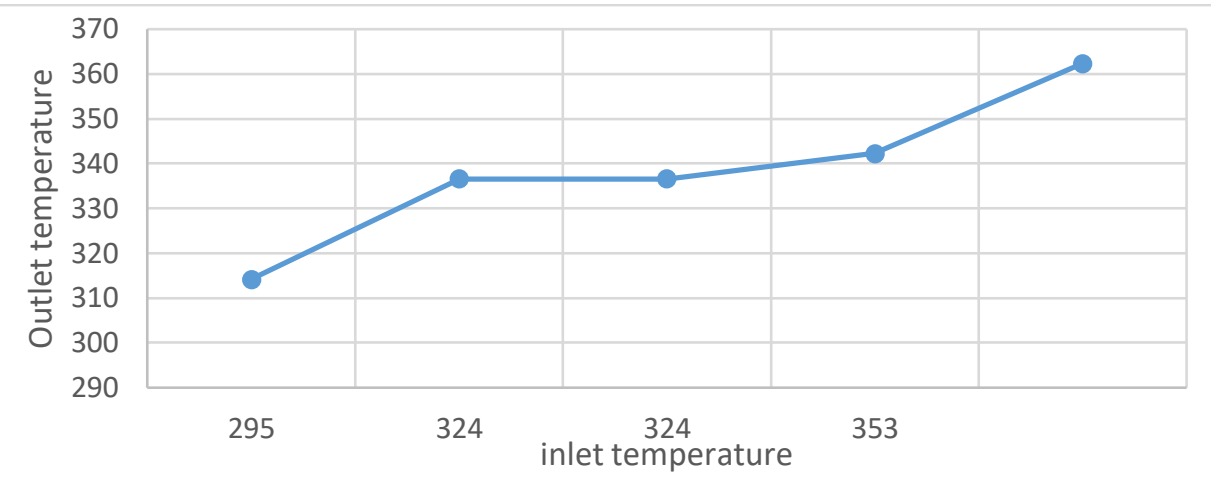

Figure 6. A graph of outlet temperature against inlet temperature.

Figure 6 shows the correlation between the input parameter and the response parameter. The outlet temperature is the response parameter and the inlet temperature is the input parameter. An increase in the inlet temperature lead to an increase in the outlet temperature. A correlation of 0.687 was achieved when Response Surface Methodology was used, this shows that there is a correlation between the input factor and the response parameter.

\section{Response 1 Efficiency \\ Transform: Power \\ Lambda: 2.37 Constant: 0.297 \\ Backward Elimination Regression with Alpha to Exit $=0.100$ \\ Forced Terms: Intercept}

Table 4. ANOVA for Response Surface Reduced Quadratic Model.

\begin{tabular}{|c|c|c|c|c|c|}
\hline Source & $\begin{array}{c}\text { Sum of } \\
\text { Squares }\end{array}$ & Df & $\begin{array}{c}\text { Mean } \\
\text { Square }\end{array}$ & $\begin{array}{c}\text { F } \\
\text { Value }\end{array}$ & $\begin{array}{c}\text { p-value } \\
\text { Prob > F }\end{array}$ \\
\hline Model & 3.29 & 3 & 1.10 & 49.10 & $<0.0001$ \\
\hline B-Day & $2.981 E-004$ & 1 & $2.981 E-004$ & 0.013 & 0.9098 \\
\hline $\begin{array}{c}\text { C-Inlet } \\
\text { Temperature }\end{array}$ & 3.00 & 1 & 3.00 & 134.07 & $<0.0001$ \\
\hline$B^{2}$ & 0.30 & 1 & 0.30 & 13.20 & 0.0030 \\
\hline Residual & 0.29 & 13 & 0.022 & & \\
\hline Lack of Fit & 0.29 & 9 & 0.032 & & \\
\hline Pure Error & 0.000 & 4 & 0.000 & & \\
\hline Cor Total & 3.58 & 16 & & & \\
\hline
\end{tabular}

Table 5. Analysis of variance.

\begin{tabular}{|c|c|c|c|c|c|c|}
\hline & Coefficient & & Standard & 95\% CI & 95\% CI & \\
\hline Factor & Estimate & df & Error & Low & High & VIF \\
\hline Intercept & 0.79 & 1 & 0.050 & 0.68 & 0.89 & \\
\hline B-Day & $-6.194 \mathrm{E}-003$ & 1 & 0.053 & -0.12 & 0.11 & 1.00 \\
\hline $\begin{array}{c}\text { C-Inlet } \\
\text { Temperature }\end{array}$ & -0.61 & 1 & 0.053 & -0.73 & -0.50 & 1.00 \\
\hline $\mathrm{B}^{2}$ & 0.26 & 1 & 0.073 & 0.11 & 0.42 & 1.00 \\
\hline
\end{tabular}

Considering Table 4 and 5 of the flat plate solar collector, the model F-value implies that the model is significant. Values of "Prob $>$ F" less than 0.0500 indicate that the model terms are significant. In this case $\mathrm{C}$ - inlet temperature and $\mathrm{B}^{2}$ are more significant model terms. Values greater 0.1000 indicates that the model terms are less significant. Equations 1 and 2 are relations to predict the efficiency of the flat plate solar collector. 
Final Equation in Terms of Coded Factors:

$(\text { Efficiency }+0.30)^{2.37}=7.895-0.0006194 B-0.61 C+0.26 B^{2}$

Final Equation in Terms of Actual Factors:

$(\text { Efficiency }+0.30)^{2.37}=7.895-\left(2.950 \times 10^{-3}\right)$ Day -0.021 Inlet temp $+\left(7.968 \times 10^{6}\right)$ Day ${ }^{2}$

The ANOVA Table confirms the adequacy of the quadractic model ( the model Prob $>\mathrm{F}$ is less than 0.05), the probability values for each individual term in the model is shown as displayed. When the probability values is greater than 0.10 , it is best to consider removing the terms for proper modelling.

\section{Response 2: Outlet Temperature}

Transform: Power, Lambda: 2.8, Constant: 0

Backward Elimination Regression with Alpha to Exit $=0.100$

Forced Terms: Intercept

Table 6. ANOVA for Response Surface Reduced Quadratic Model.

\begin{tabular}{|c|c|c|c|c|c|}
\hline & Sum of & & Mean & F & p-value \\
\hline Source & Squares & df & Square & Value & Prob > F \\
\hline Model & $5.725 \mathrm{E}+013$ & 6 & $9.541 \mathrm{E}+012$ & 51247.08 & $<0.0001$ \\
\hline A-Hour Angle & 0.000 & 1 & 0.000 & 0.000 & 1.0000 \\
\hline B-Day & $4.182 E+008$ & 1 & $4.182 E+008$ & 2.25 & 0.1648 \\
\hline -Inlet Temperature & $2.684 E+013$ & 1 & $2.684 E+013$ & $1.442 E+005$ & $<0.0001$ \\
\hline$A^{2}$ & $5.301 E+009$ & 1 & $5.301 E+009$ & 28.47 & 0.0003 \\
\hline$B^{2}$ & $3.020 E+013$ & 1 & $3.020 E+013$ & $1.622 E+005$ & $<0.0001$ \\
\hline$C^{2}$ & $3.463 E+011$ & 1 & $3.463 E+011$ & 1859.87 & $<0.0001$ \\
\hline Residual & $1.862 \mathrm{E}+009$ & 10 & $1.862 \mathrm{E}+008$ & & \\
\hline Lack of Fit & $1.862 E+009$ & 6 & $3.103 E+008$ & & \\
\hline Pure Error & 0.000 & 4 & 0.000 & & \\
\hline Cor Total & $5.725 \mathrm{E}+013$ & 16 & & & \\
\hline
\end{tabular}

Table 7: Analysis of variance table.

\begin{tabular}{|l|l|c|l|l|l|l|}
\hline & Coefficient & & Standard & 95\% CI & 95\% CI & \\
\hline Factor & Estimate & Df & Error & Low & High & VIF \\
\hline Intercept & $1.191 \mathrm{E}+007$ & 1 & 6102.16 & $1.189 \mathrm{E}+007$ & $1.192 \mathrm{E}+007$ & \\
\hline A-Hour Angle & 0.000 & 1 & 4824.18 & -10748.94 & 10748.94 & 1.00 \\
\hline B-Day & -7230.16 & 1 & 4824.18 & -17979.10 & 3518.77 & 1.00 \\
\hline $\begin{array}{l}\text { C-Inlet } \\
\text { Temperature }\end{array}$ & $1.832 \mathrm{E}+006$ & 1 & 4824.18 & $1.821 \mathrm{E}+006$ & $1.842 \mathrm{E}+006$ & 1.00 \\
\hline $\mathrm{A}^{2}$ & 35480.83 & 1 & 6649.67 & 20664.44 & 50297.22 & 1.01 \\
\hline $\mathrm{B}^{2}$ & $2.678 \mathrm{E}+006$ & 1 & 6649.67 & $2.663 \mathrm{E}+006$ & $2.693 \mathrm{E}+006$ & 1.01 \\
\hline $\mathrm{C}^{2}$ & $-2.868 \mathrm{E}+005$ & 1 & 6649.67 & $-3.016 \mathrm{E}+005$ & $-2.720 \mathrm{E}+005$ & 1.01 \\
\hline
\end{tabular}

Considering Table 6 and 7 of the flat plate solar collector, the model F-value implies that the model is significant. Values of "Prob $>$ F" less than 0.0500 indicate that the model terms are significant. In this case $\mathrm{C}$ - inlet temperature, $\mathrm{A}^{2}, \mathrm{~B}^{2}$ and $\mathrm{C}^{2}$ are more significant model terms. Values greater 0.1000 indicates that the model terms are less significant. Equations 3 and 4 are relations to predict the outlet temperature of the flat plate solar collector. 


\section{Final Equation in Terms of Coded Factors:}

$$
\begin{aligned}
& (\text { outlet temp })^{2.8}=+1.19 \times 10^{7}-7230.16 \mathrm{~B}+1.83 \times 10^{6} \mathrm{C}+35480.83 \mathrm{~A}^{2}+2.68 \times \\
& 10^{6} \mathrm{~B}^{2}-2.87 \times 10^{5} \mathrm{C}^{2}
\end{aligned}
$$

\section{Final Equation in Terms of Actual Factors:}

$(\text { outlet temp })^{2.8}=-4.16 \times 10^{7}-29629.65$ Day $+2.84 \times 10^{5}$ Inlet Temp + 17.52Hour Angle ${ }^{2}+80.84(\text { Day })^{2}-340.99(\text { Inlet temp })^{2}$

The ANOVA Table confirms the adequacy of the quadractic model ( the model Prob $>\mathrm{F}$ is less than 0.05 ), the probability values for each individual term in the model is shown as displayed. When the probability values is greater than 0.10 , it is best to consider removing the terms for proper modelling.

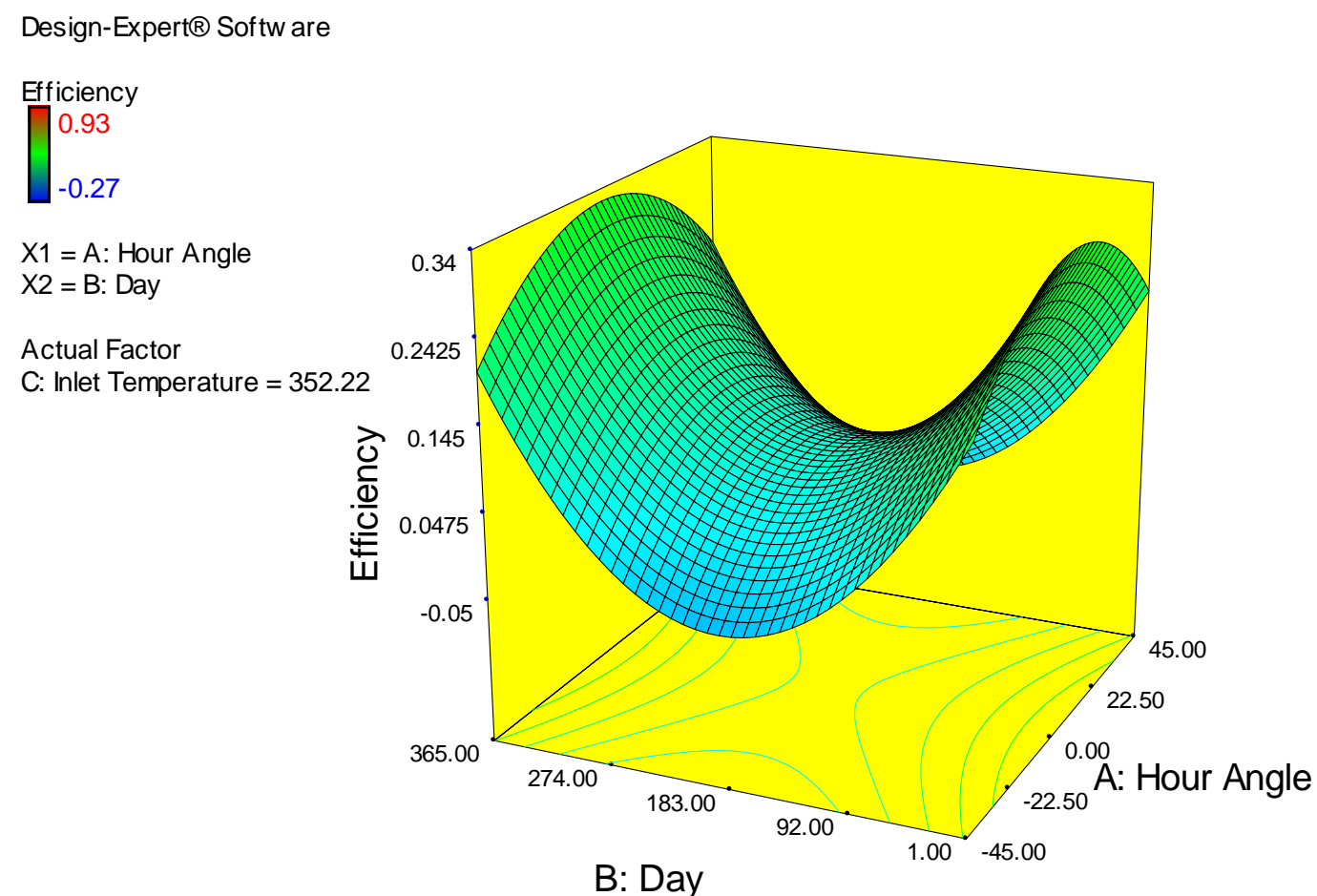

Figure 7. A 3D graph of efficiency against day and hour angle.

The 3D graph of efficiency against day and hour angle shows that at an inlet temperature of $352.22^{\circ} \mathrm{C}$, it can be observed that the maximum efficiency is at a value of 52 percent in January with a temperature of $353 \mathrm{~K}$. This is because at this temperature the system may lose temperature to the plate. Little consideration will show temperature difference between the plate and fluid temperature is proportional to efficiency and thus at higher temperatures the efficiency undergoes a steady drop. Low inlet temperature may increase efficiency by 36 percent for days at the beginning and tail end of the year and a drop in maximum efficiency.

It gets to its bottom point at 183 day of the year. These results are obtainable at an hour angle of 0 degrees. However as the hour angles passes noon, the efficiency increases for all days from 1-365 at all inlet temperatures. The range of efficiency tends to increase as hour angle moves towards noon for a single day and difference in inlet temperature. The efficiency rises to almost 
93 percent at $3 \mathrm{pm}$ in January when the inlet temperature is at room temperature but drop to zero at $353 \mathrm{~K}$. The hour angle seems to have little effect on the efficiency of the system.

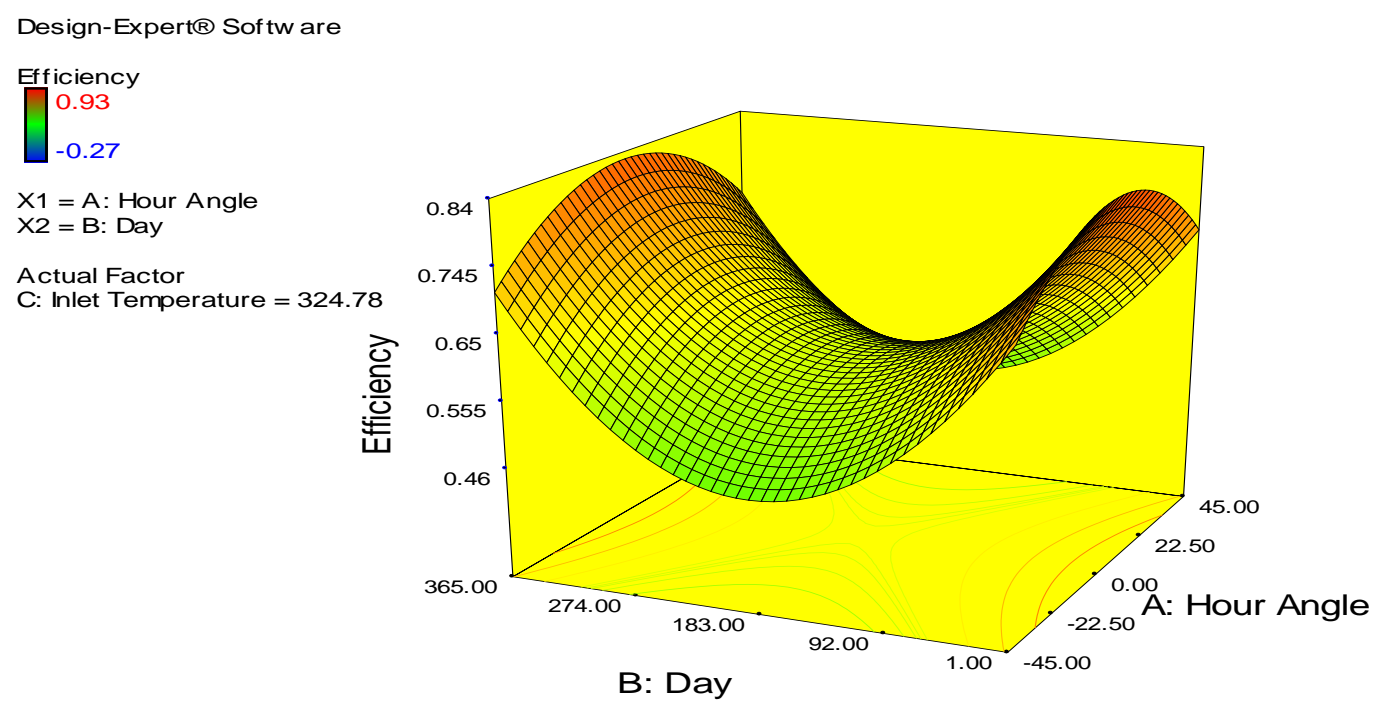

Figure 8. A 3D graph of efficiency against day and hour angle.

The 3D graph of efficiency against day and hour angle shows that at an inlet temperature of $324.78^{\circ} \mathrm{C}$, a reduction in the number of days lead to a decrease in efficiency towards the mid-point of 183 days. As observed from the mid-point to the end, there was an increase in the efficiency and the hour angle. This implies that January, February and March which has a midmonth with lower days has more efficiency and it drops while approaching the middle of the year which is the raining season and it rises towards the end of the year (September, October, November and December). The colour indication at the edge of the 3D graph shows that using inlet temperature of $324.78^{\circ} \mathrm{C}$ allows only the months close to the edge, which is January and December get an efficiency that is close to 0.93 .

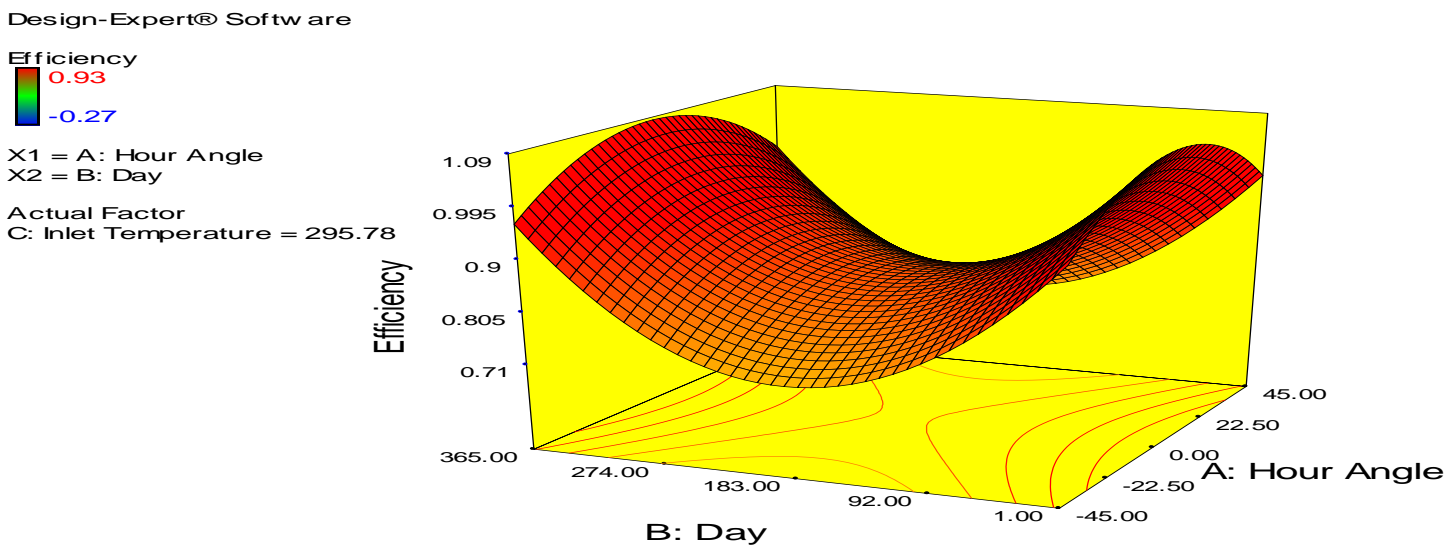

Figure 9. A 3D graph of efficiency against day and hour angle.

The 3D graph of efficiency against day and hour angle shows that at an inlet temperature of $295.78^{\circ} C$, a decrease in the number of days causes a decrease in efficiency towards the midpoint considering it at 183 days as shown in figure 9 . As observed from the mid-point to the tail end there is an increase in efficiency, as the hour angle increases there is also an increase in the efficiency. This implies that January, February and March which has a mid-month with lower 
days has more efficiency and it drops while approaching the middle of the year which is the raining season and it rises towards the end of the year (September, October, November and December). Looking at the colour of the 3D graph which appears red in almost all its part as indicated on the efficiency factor key (turning red is attaining close to 0.93 efficiency and blue is moving away from the efficiency). An outlet temperature of $295.78^{\circ} \mathrm{C}$ shows that almost all part of the year can attain 0.93 efficiency but it is darker at the edge, indicating January, February, March, fairly April, September, October, November and December can achieved maximum efficiency of 0.93 .

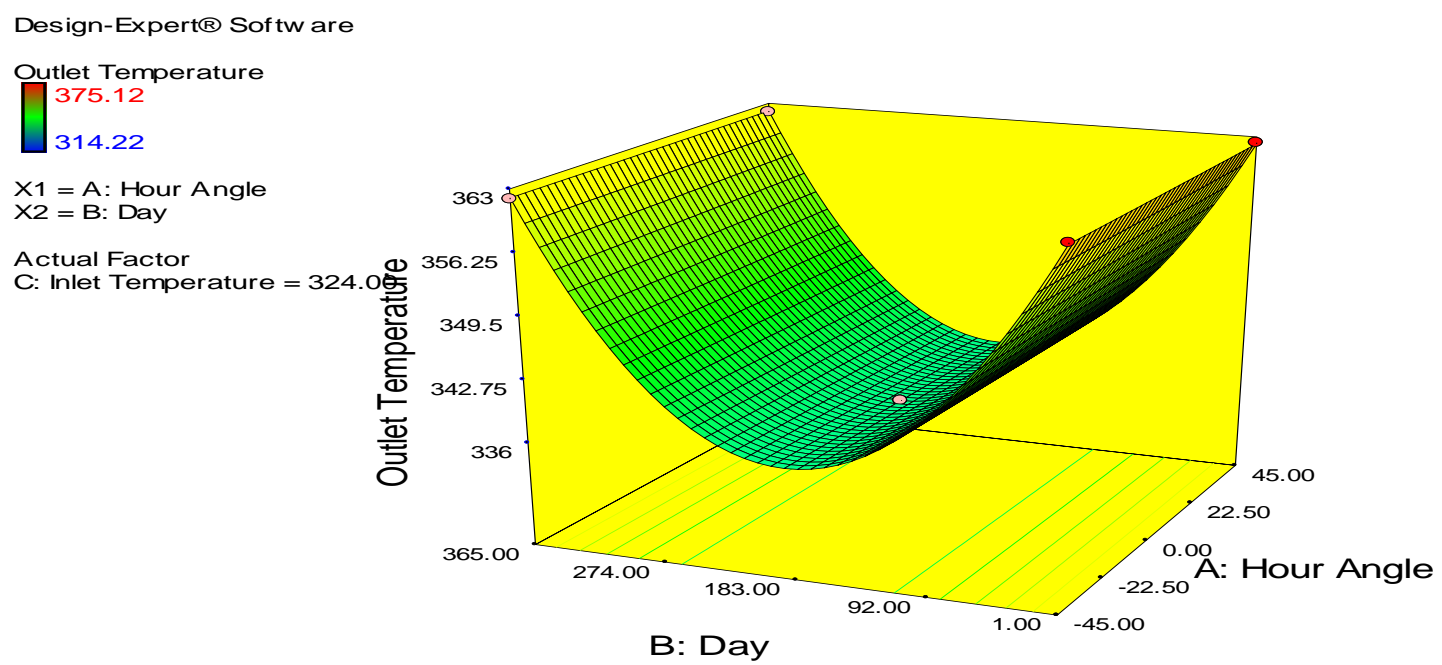

Figure 10. A 3D graph of outlet temperature against day and hour angle.

The 3D graph of efficiency against day and hour angle shows that at an inlet temperature of $324.00^{\circ} \mathrm{C}$, a reduction in the number of days causes a decrease in outlet temperature towards the mid-point of about 183 days. From the mid-point to the tail end, there is an increase in outlet temperature. As the hour angle increase there is also an increase in the outlet temperature. This implies that January, February and March which has a mid-month with lower days has more outlet temperature and it drops while approaching the middle of the year which is the raining season and it rises towards the end of the year (September, October, November and December). Using an inlet temperature of $324.00^{\circ} \mathrm{C}$ it shows on the $3 \mathrm{D}$ graph as indicated by the colour paterns that the outlet temperature of $375.12^{\circ} \mathrm{C}$ cannot be achieved.

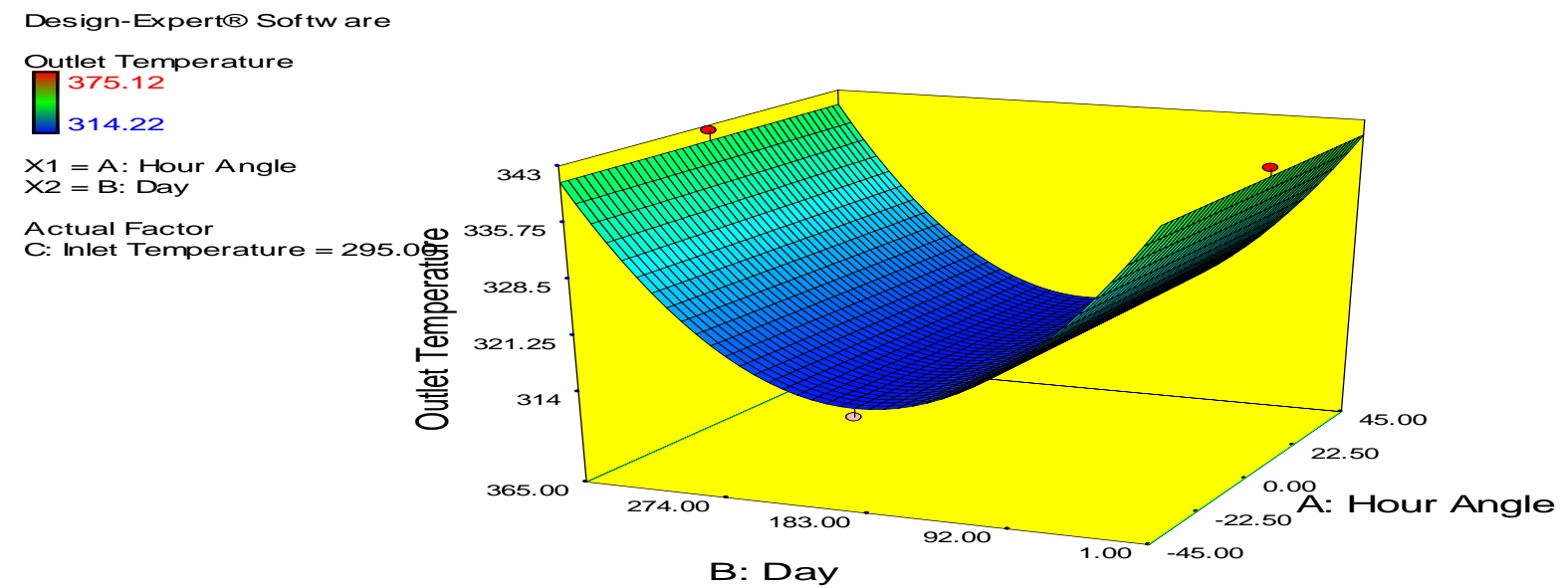

Figure 11. A 3D graph of outlet temperature against day and hour angle. 
The 3D graph of efficiency against day and hour angle shows that at an inlet temperature of $295.00^{\circ} \mathrm{C}$, a reduction in the number of days causes a decrease in the outlet temperature as it tends towards the mid-point of the graph but after the mid-point and moving towards the tail end, the outlet temperature increases. An increase in the hour angle leads to an increase in the outlet temperature. This implies that January, February and March which has a mid-month with lower days has more outlet temperature and it drops while approaching the middle of the year which is the raining season and it rises towards the end of the year (September, October, November and December). Using an inlet temperature of $295.00^{\circ} \mathrm{C}$ it shows on the $3 \mathrm{D}$ graph using the colour pattern that the outlet temperature of $375.12^{\circ} \mathrm{C}$ cannot be achieved.

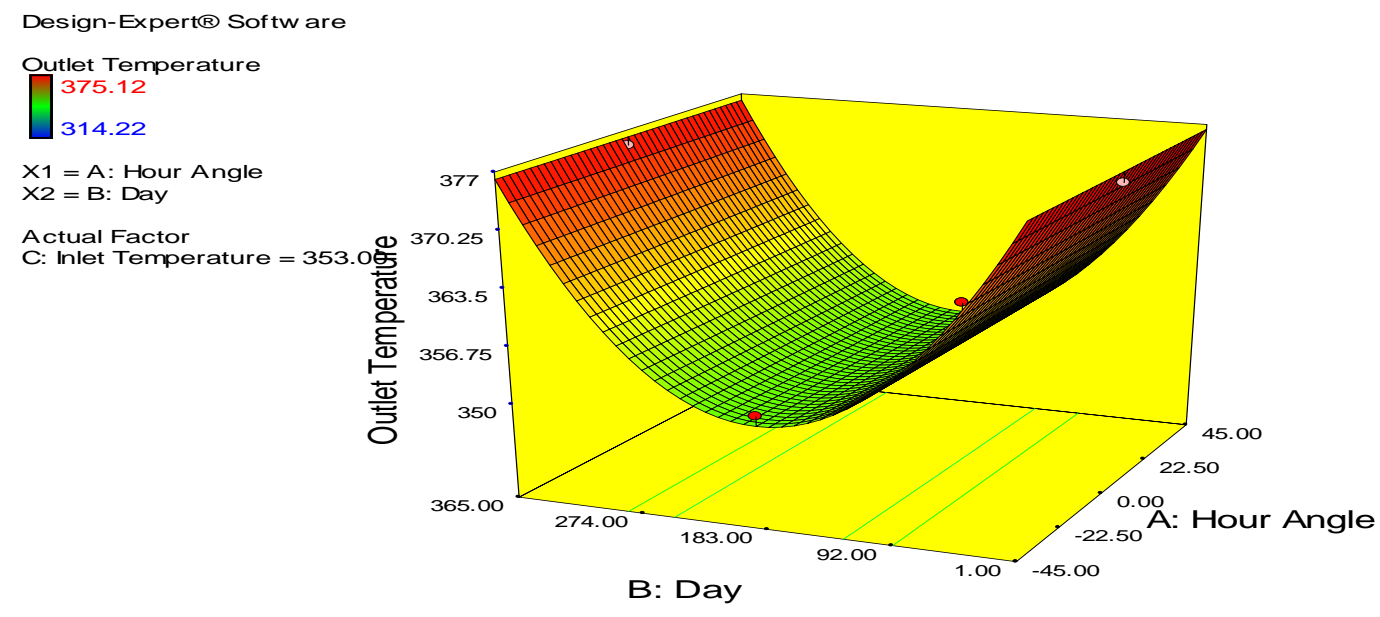

Figure 12. A 3D graph of outlet temperature against day and hour angle.

The 3D graph of efficiency against day and hour angle shows that at an inlet temperature of $353.00^{\circ} \mathrm{C}$, a reduction in the number of days causes a decrease in outlet temperature till it gets to the mid-point of 183 days and from the mid-point the curve tends to move upwards, causing an increase in outlet temperature. An increase in hour angle also leads to an increase in outlet temperature. This implies that January, February and March which has a mid-month with lower days has more outlet temperature and it drops while approaching the middle of the year which is the raining season and it rises towards the end of the year (September, October, November and December). Using an inlet temperature of $353.00^{\circ} \mathrm{C}$ it shows on the $3 \mathrm{D}$ graph from the colour pattern that the outlet temperature of $375.12^{\circ} \mathrm{C}$ can be achieved by the months closer to the edges of the curve.

\section{CONCLUSION}

In this study a model was developed to effectively predict the output temperature and efficiency of the solar thermal system. The response parameters and the considered input parameters were output temperature, efficiency and hour angle, day, input temperature respectively. It was found that the temperatures and solar radiation were higher at the beginning and ending of the year, the months at the middle of the year experience a reduction in temperature and solar radiation due to the rainy season.

January, February, March, fairly April and September, October, November, and December experience a higher temperature and solar radiation respectively. 


\section{REFERENCES}

[1] Adnan, Q., Badescu, V. and Soriga. I. (2015) Hybrid solar collector for water and air heating: effects of storage tank volume and air channel shape on efficiency U.P.B. Sci. Bull., Series D77 (3) pp 29-40.

[2] Hamed, M., Fellah, A. and Ben B.A. (2014) Parametric sensitivity studies on the performance of a flat plate solar collector in transient behavior Energy Conversion and Management 78 7th International Conference on Advanced Concepts in Mechanical Engineering IOP Publishing IOP Conf. Series: Materials Science and Engineering 147 (2016) 012146 doi:10.1088/1757-899X/147/1/012146 pp 938-947.

[3] Hottel, H.C. and Woertz, B.B. (2000) Performance of flat plate solar heat collectors Trans. ASME 64 pp 91.

[4] Paulescu, M., Dughir, C., Tulcan-Paulescu. E., Lascu, M., Gravila, P. and Jurca, T. (2010) Solar Radiation Modeling and Measurements in Timisoara, Romania: Data and Model Quality Environmental Engineering and Management Journal 9(8) pp 1089-1095.

[5] Stanciu, C. and Stanciu, D. (2014) Optimum tilt angle for flat plate collectors all over the World - A declination dependence formula and comparisons of three solar radiation models Energy Conversion and Management 81 pp 133-143.

[6] Duffie, J.A. and Beckman, W.A. (2006) Solar Engineering of Thermal Processes, 3rd ed. (Hoboken: John Wiley \&Sons). 